\title{
DEFORMATION PARAMETERS AND FATIGUE OF THE RECYCLED ASPHALT MIXTURES
}

\author{
Juraj ŠRÁMEK ${ }^{1, *}$ \\ ${ }^{1}$ Department of Construction Management, Faculty of Civil Engineering, University of Žilina, \\ Univerzitná 1, 01026 Žilina, Slovakia. \\ corresponding author: juraj.sramek@fstav.uniza.sk.
}

\section{Abstract}

The deformational properties of asphalt mixtures measured by dynamic methods and fatigue allow a design the road to suit the expected traffic load. Quality of mixtures is also expressed by the resistance to permanent deformation. Complex modulus of stiffness and fatigue can reliably characterize the proposed mixture of asphalt pavement. The complex modulus $\left(E^{*}\right)$ measurement of asphalt mixtures are carried out in laboratory of Department of Construction Management at University of Žilina by two-point bending test method on trapezoid-shaped samples. Today, the fatigue is verified on trapezoid-shaped samples and is assessed by proportional strain at 1 million cycles $\left(\varepsilon_{6}\right)$. The test equipment and software is used to evaluate fatigue and deformation characteristics.
\end{abstract}

\author{
Keywords: \\ Asphalt mixtures; \\ Recycling fatigue; \\ Deformation parameters; \\ Complex modulus.
}

\section{Introduction}

Deformation and resistance characteristics and fatigue of asphalt mixtures have the eminent influence on asphalt pavements operational performance. Until now, deformation properties assessment is realized on principle of dynamic (impact) test and fatigue life of asphalt pavement, on principle of resistance decrease or deformation increase in different binders and mixtures characteristics. Nowadays, it's used the standard for measurement of complex modulus and fatigue of the asphalt reinforced materials („mixtures“), which gives better description of the car axel during normal operation at the frequency from 6 to $25 \mathrm{~Hz}$. The complex modulus $\left(E^{*}\right)$ measurement of asphalt mixtures are carried out in laboratory of Department of Construction Management at University of Žilina by two-point bending test method on trapezoid-shaped samples. Today, the fatigue is verified on trapezoid-shaped samples and is assessed by proportional strain at 1 million cycles $\left(\varepsilon_{6}\right)$. The test equipment and software called KATEMS is used to evaluate fatigue and deformation characteristics.

\section{Test equipment}

The tests of the complex modulus and fatigue were carried out in the laboratory of Department of Construction Management of University of Žilina. Bending tests are widely used for measuring the stiffness modulus and assessing the fatigue resistance of asphaltic paving materials. The twopoint bending test on trapezoidal specimens is, arguably, the most repeatable and reproducible bending test method detailed in the relevant STN EN 12697 standards. In this test the specimen is mounted as a vertical cantilever. The base is fixed and the top is moved sinusoidally with a constant displacement amplitude. The trapezoidal shape ensures that the maximum values of bending stress and strain occur away from the ends of the specimen where there are likely to be stress concentrations.

With the Cooper Technology equipment, two trapezoidal specimens are tested simultaneously and stiffness modulus can be determined at a range of frequencies and temperatures. In the fatigue test the specimens are subjected to a constant strain amplitude at a selected frequency and temperature until the stiffness modulus decreases to a user-selected target level (normally 50 percent of its initial value).

The equipment (Fig. 1) works with constant deviation. Rigid test frame housed within temperature cabinet range -20 to $30^{\circ} \mathrm{C}$. Frequency ranges from 0.1 to $30 \mathrm{~Hz}$. Precise manual setting 
of strain amplitude. Accurate pre-test displacement transducer adjustment was carried out by using software feedback. Two high-precision $\pm 2.5 \mathrm{kN}$ fatigue rated piezoelectric force transducers.

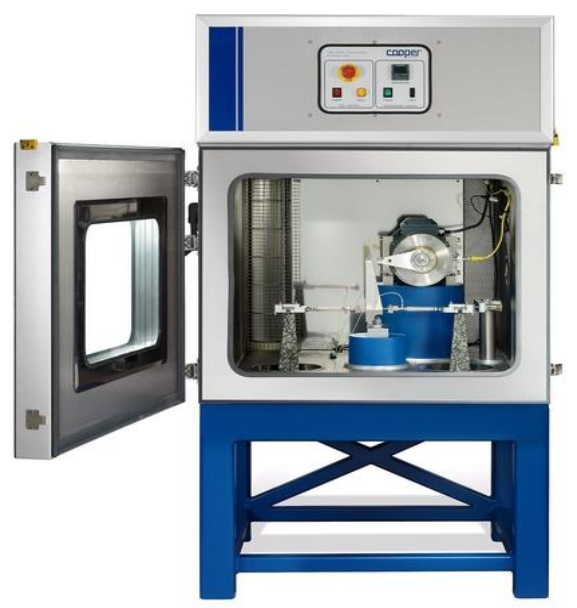

Fig. 1: Two-point trapezoidal bending beam machine [7].

\section{Measurements principle of deformational properties and fatigue of two-point bending test}

The rheology characters materials are tested with the complex modulus method [2] [3].

The basic deformation characteristics include modulus of elasticity, deformation modulus, modulus of stiffness, creep modulus, Poisson's ratio.

Complex modulus is the ratio of tension and deformation at steady, harmonically variable oscillation in consideration of their mutual time shift.

$$
E^{*}=\frac{\sigma_{0}}{\varepsilon_{0}}=\left(E_{1}^{2}+E_{2}^{2}\right)^{\frac{1}{2}} \text {. }
$$

Fatigue is decrease of material resistance by repetitive loading in comparison with resistance by single loading STN EN12697-24.

According to the Slovak dimensioning method the fatigue is given by:

$S=a-b \cdot \log N_{i}$,

where: $a, b$ - fatigue coefficients,

$N_{i}$ - number of load cycles.

Measurement of the complex stiffness modulus is performed at the short-term alternating harmonic load. It expresses the proportion of maximum amplitudes of excitation tension $\left(\sigma_{0}\right)$ and deformation induced by it $\left(\varepsilon_{0}\right)$ and their phase shift $(\varphi)$. The stress (force), which varies sinusoidally in time, is applied on to the element of linear viscoelastic material, the strain (deformation) varies in time with the same frequency as the stress, but it lags behind by the phase. Graphical representation of measurement and complex modulus evaluation is represented in Fig. 2. 12697-26).

The measurements were performed on trapezoidal specimens according to Fig. 3 (STN EN 


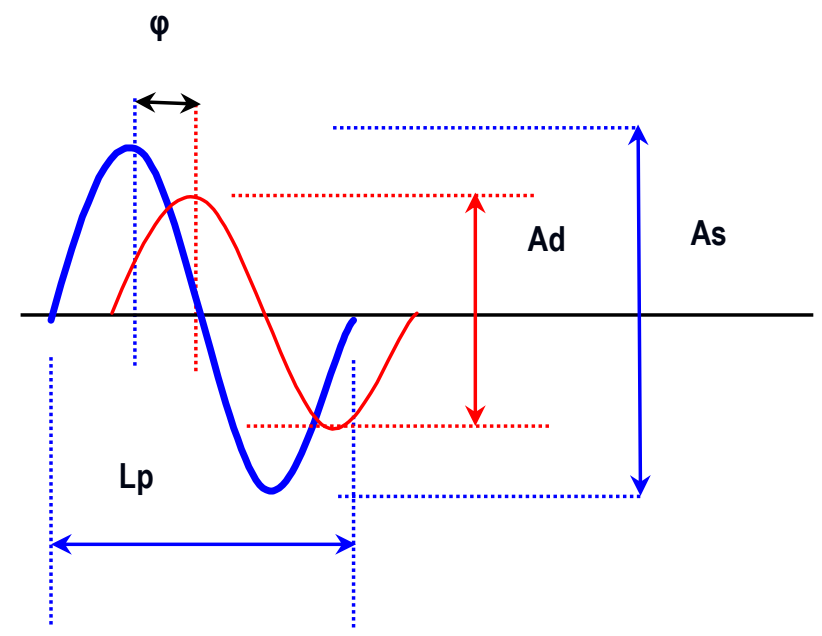

Fig. 2: Measurement of complex modulus; Lp - length of period; $\varphi$ - phase-shift; As - amplitude forces; Ad - amplitude deformation.

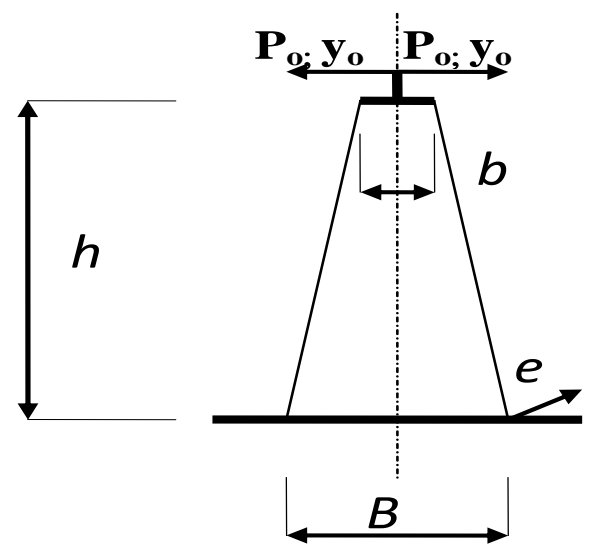

Fig. 3: Scheme of measuring and Dimensions of test samples; $B=56 \mathrm{~mm} ; b=25 \mathrm{~mm} ; \mathrm{e}=25 \mathrm{~mm}$; $\mathrm{h}=250 \mathrm{~mm}$ for the mixture with $\mathrm{D} \leq 14 \mathrm{~mm} ; \mathrm{P}_{0}$ - acting force; $\mathrm{y}_{0}$ - deformation [2].

\section{Tested mixtures and measurements results}

The measurements were carried out on the test specimen trapezoidal shape for recycled asphalt mixture AC 16 L; II. (there was used $100 \%$ recycled mixture).

The measuring of complex modulus was performed in temperatures ranging from $+5{ }^{\circ} \mathrm{C}$ to $+25^{\circ} \mathrm{C}$. The results of complex modulus of recycled asphalt mixture for different temperatures are listed in Table 1 and Fig. 4. Relevant for classification into categories is measuring by temperature $+15^{\circ} \mathrm{C}$ and frequency $10 \mathrm{~Hz}$.

Table 1: Complex modulus of the recycled asphalt mixture.

\begin{tabular}{|c|c|c|c|}
\hline Frequency (Hz) & \multicolumn{3}{|c|}{ Complex modulus (MPa) } \\
\hline 5 & 9520.4 & 5246.8 & 4172.2 \\
\hline $\mathbf{1 0}$ & 9989.7 & $\mathbf{6 1 9 2 . 6}$ & 4462.0 \\
\hline 15 & 10455.8 & 6611.9 & 4990.6 \\
\hline 20 & 10583.9 & 6596.6 & 5362.3 \\
\hline 25 & 10768.4 & 7011.0 & 5821.5 \\
\hline Temperature $\left({ }^{\circ} \mathrm{C}\right)$ & 5 & $\mathbf{1 5}$ & 25 \\
\hline
\end{tabular}




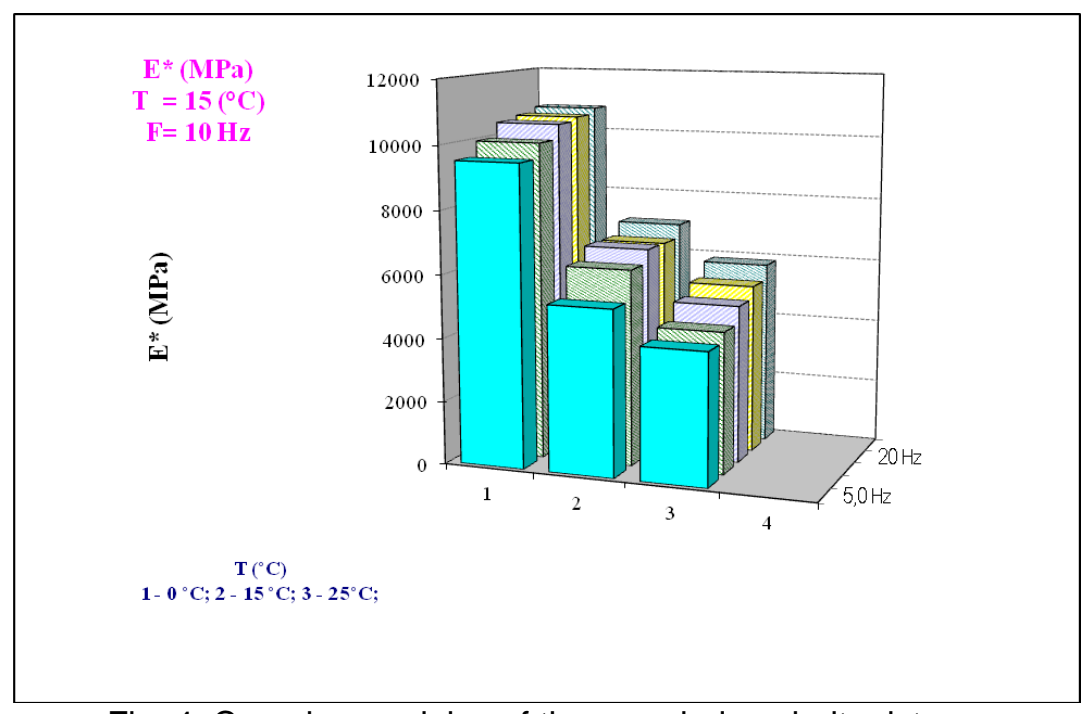

Fig. 4: Complex modulus of the recycled asphalt mixture.

Classification of the asphalt mixtures according to values of deformation characteristics is shown in Table 2 (STN EN 13 108-1). Measured recycled mixtures as classified in Category $S_{\text {min }} 5500$.

Table 2: Minimal stiffness, $S_{\min }[1]$.

\begin{tabular}{|c|c|c|c|}
\hline $\begin{array}{c}\text { Minimal } \\
\text { stiffness }\end{array}$ & Category & $\begin{array}{c}\text { Minimal } \\
\text { stiffness }\end{array}$ & Category \\
\hline $\mathbf{M P a})$ & $\boldsymbol{S}_{\min }$ & $\mathbf{( M P a )}$ & $\boldsymbol{S}_{\min }$ \\
\hline 21000 & $S_{\min 21000}$ & 4500 & $S_{\min 4500}$ \\
\hline 17000 & $S_{\min 17000}$ & 3600 & $S_{\min 3600}$ \\
\hline 14000 & $S_{\min 14000}$ & 2800 & $S_{\min 2800}$ \\
\hline 11000 & $S_{\min 11000}$ & 2200 & $S_{\min 2200}$ \\
\hline 9000 & $S_{\min 9000}$ & 1800 & $S_{\min 1800}$ \\
\hline 7000 & $S_{\min 7000}$ & 1500 & $S_{\min 1500}$ \\
\hline $\mathbf{5 5 0 0}$ & $S_{\min 5500}$ & No requests & $S_{\min 1}$ \\
\hline
\end{tabular}

The results of the measurements of the fatigue are from samples, which were loaded by temperature $+10^{\circ} \mathrm{C}$ with loading in unit of measure by frequency $25 \mathrm{~Hz}$. The fatigue line is estimated in a bi-logarithmic system as a linear regression of fatigue life versus amplitude levels. Using these results, the strain is corresponding to an average of $10^{6}$ cycles $\left(\varepsilon_{6}\right)$ and the slope of the fatigue line $1 / b$ (STN EN 12697-24).

The parameters for evaluation of fatigue are:
a) $\varepsilon_{6}$
b) $\Delta \varepsilon_{6}$,
c) slope $l / b$,
d) estimated residual standard deviation $s_{N}$,
e) correlation coefficient $r^{2}$.

The results of the fatigue are on Table 3 and the example of the mixtures fatigue in form of Wöhler's diagram is on Fig.5. 
Table 3: Fatigue of the recycled asphalt mixture.

\begin{tabular}{|c|c|c|c|c|c|c|c|c|}
\hline \multirow{2}{*}{ Mixture } & $\mathrm{T}$ & $\mathrm{F}$ & $\varepsilon_{6} \cdot 10^{-6}$ & $\mathrm{~b}$ & $\mathrm{r}^{2}$ & $s N$ & $\Delta \varepsilon_{6}$ & Category \\
\cline { 2 - 6 } & $\left({ }^{\circ} \mathrm{C}\right)$ & $(\mathrm{Hz})$ & (mikrostrain) & $(-)$ & $(-)$ & & & \\
\hline AC 16 L; II & 10 & 25 & 96.98 & 0.9836 & 0.8985 & 0.13138 & $2.91 \mathrm{E}-09$ & Fat $_{\mathrm{e} \text { min85 }}$ \\
\hline
\end{tabular}

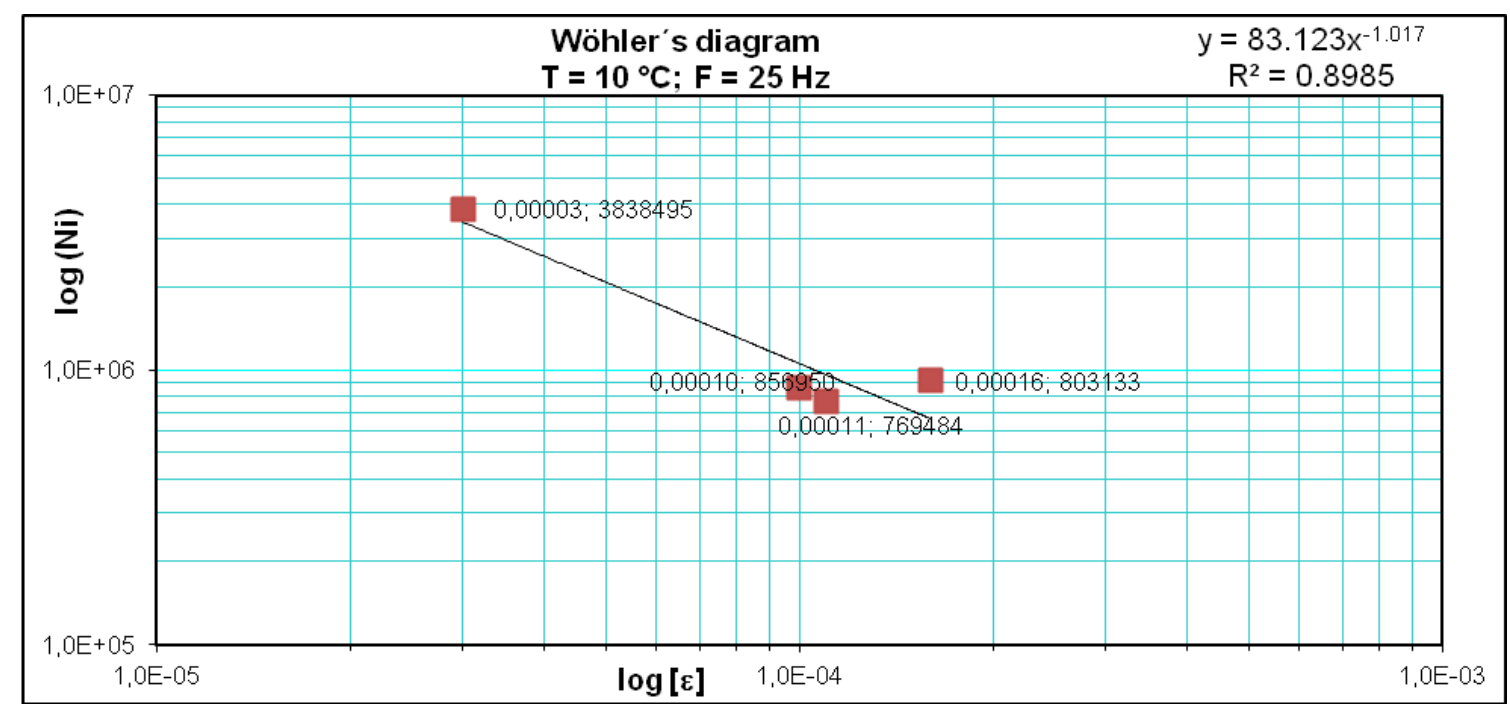

Fig. 5: Fatigue - Wöhler's diagram.

Classification of the asphalt mixtures according to values of fatigue is shown in Table 4 (STN EN 13 108-1). Measured recycled mixtures as classified in Category Fat min85.

Table 4: Values of fatigue [1].

\begin{tabular}{|c|c|c|c|}
\hline \multirow[t]{2}{*}{ Category } & Fat $_{\text {min }}$ & \multirow[t]{2}{*}{ Category } & Fat $_{\text {e min }}$ \\
\hline & (strain $\times 10^{6}$ ) & & $\left(\right.$ strain $\left.\times 10^{6}\right)$ \\
\hline Fat $_{\mathrm{e} \min 310}$ & 310 & Fat $_{\mathrm{e} \min 100}$ & 100 \\
\hline Fat $_{e \min 260}$ & 260 & Fat $_{\text {m } \min 85}$ & 85 \\
\hline Fat $_{\mathrm{e} \min 220}$ & 220 & Fat $_{\mathrm{e} \min 70}$ & 70 \\
\hline Fat $_{\mathrm{e} \min 190}$ & 190 & $\mathrm{Fat}_{\mathrm{e} \min 60}$ & 60 \\
\hline Fat $_{\mathrm{e} \min 160}$ & 160 & $\mathrm{Fat}_{\mathrm{e} \min 50}$ & 50 \\
\hline Fat $_{e \min 135}$ & 135 & Fat $_{\mathrm{e} \operatorname{minNR}}$ & - \\
\hline Fat $_{\mathrm{e} \min 115}$ & 115 & & \\
\hline
\end{tabular}

\section{Conclusions}

According to results of measurements is recycled asphalt mixture AC $16 \mathrm{~L}$; II suitable for work activities relating to the maintenance of roads, repair local disturbances and repair asphalt cover. The use of recycled materials protects the environment, reduces the usage of traditional quality materials and allows more roads to be built or repaired. Recycled mixtures can be used for pavement sub-layers and if the required criteria are met, in some cases even for pavement wearing courses.

It is recommended that the functional test of fatigue for asphalt mixtures design is used during the design of asphalt mixtures; such test will determine the mixture life expectancy of pavement regarding its operational performance. It is important to know not only the proportional strain at 1 million cycles $\varepsilon_{6}$, but also the trend of fatigue line from Wöhler diagram for the assessment of mixtures following fatigue resist. 


\section{Acknowledgement}

The research is supported by European regional development fund and Slovak state budget by the project "Research centre of University of Žilina", ITMS 26220220183.

\section{References}

[1] STN EN 13 108-1 Asfaltové zmesi. Požiadavky na materiály. Čast' 1: Asfaltový betón.

[2] EN 12697-26:2007 (S): Bituminous mixtures - Test methods for hot mix asphalt - Part 26: Stiffness.

[3] EN12697-24:2003 (E): Bituminous mixtures - Test methods for hot mix asphalt - Part 24: Resistance to fatigue.

[4] SCHLOSSER, F. - MIKOLAJ, J. - ZATKALÍKOVÁ, V. - ŠRÁMEK, J. - ĎUREKOVÁ, D. REMEK, L.: Deformation Properties and Fatigue of Bituminous Mixtures. Advances in materials Science and Engineering - Mechanical properties and Nondestructive Testing of Advanced Materials, Hindawi Publishing Corporation, Volume 2013.

[5] SCHLOSSER, F. - ZGÚTOVÁ, K. - HÍREŠ, V. - NEMEC, B. - KRIŽOVENSKÁ, E. - ŠRÁMEK, J.: Deformation Parameters of the Asphalt Mixtures in Pavement Construction Layers. World Road Congress Roads for a better life Mobility, sustainability and development, Mexico City (2011).

[6] KRIŽOVENSKÁ, E.: Deformačné vlastnosti materiálov stmelených asfaltom. (Deformation properties of reinforced materials). Doktorandská dizertačná práca. Žilinská univerzita $v$ Žiline (2011).

[7] SCHLOSSER, F. - ĎUREKOVÁ, D.: 2014. Rheological properties of asphalt mixtures with additives. In: Advances in materials research.

[8] http://cooper.co.uk/. 